NOTICEBOARD

\title{
3rd European Conference on Psychological Assessment
}

\section{Call for Papers}

The 1995 Conference of the European Association of Psychological Assessment (EAPA) will be held at the University of Trier, Germany, on August 27-30, 1995. The conference covers a variety of topics, such as diagnostic processes, assessment in personality, intelligence, behaviour, neuropsychology or psychophysiology as well as the assessment in the different applied fields such as clinical and health, education, work or evaluation research. The official organ of the EAPA is the European Journal of Psychological Assessment.

Persons wishing to organize a symposium, to present a paper or a poster should send

1. a title,

2. an abstract of about 150 words for the programme book (paper and diskette version),

3. name(s) and institutional affiliation(s) of the author(s). If there is more than one author, please indicate who will present the paper,

4. some keywords,

5. an electronic mail address, if available.

Submissions should be related to the above mentioned areas. An overhead projector and a $35 \mathrm{~mm}$ slide projector will be available. Twenty minutes of programme time is suggested for paper presentations (discussion included).

The deadline is

\section{March 1995}

for receipt of paper and symposium proposals. Submissions of paper and symposium proposals as well as requests for information should be sent to

Christine Telser, 3rd ECPA, University of Trier, FB I-Psychology, Building DM, D-54286 Trier. Phone: + 49 (651) 201-3257, Fax: + 49 (651) 201-3953, E-mail: STEYER@pcmail.uni-trier.de

A special effort will be made to invite participants from the East and South European countries. 